$\xi^{2}=1$ 줄

\title{
Application of VLF-EM method for base metal exploration in Gwani area (Misau 107), Jigawa state, Nigeria
}

\author{
Mubarak Umar Faruk* \\ M. Sc Mineral Exploration, University of Jos, Nigeria \\ *Corresponding author E-mail: mbrkfaruk@gmail.com
}

\begin{abstract}
The Very Low Frequency (VLF) electromagnetic (EM) survey is a reliable technique for identifying network of fractures usually hidden by overburden materials that overlie the crystalline basement. The Gwaram area, Jigawa state of Nigeria is underlain by Older Granite of the basement complex of Nigeria, with predominant rock type being coarsely porphyritic biotite granite. The project is aimed at confirming the occurrence of sulphide mineralization within the study area, using both the geological information and VLF techniques. Measurements involving 10 profiles spaced $50 \mathrm{~m}$ interval were collected within the study area, using the transmitter of Le Blanc in France whose radio frequency is $18.3 \mathrm{kHz}$. Profiles 1-10 show the respective cross-over points (points of intersection) at 430, 460, 430, 470, 480, $500,550,560,610$, and $620 \mathrm{~m}$ with a positive in-phase response of 11.1, 7.3, 22.1, 23.7, 30.8, 36.2, 29.5, 17.6 and 20.8\% respectively, the suspected fault occurred at respective depth of 45,130,150,135,150,135, 140,145, 145 and $125 \mathrm{~m}$. The ratios of primary to secondary electromagnetic anomalies on the ten profiles are not constant and their profile shapes are never identical or consistent. Such anomalies at cross-over points have been used to infer the presence of fracture. All the profiles show one identical anomaly which is suspected to be a hydrothermal zone or mineralized fault. VLF-EM contour and 3D map were produced and indicate that there is high conductivity toward the southwest of the map. The results obtained in the survey inferred that the deposit is expected to be economically viable.
\end{abstract}

Keywords: VLF-EM; Frequency; In-Phase; Quadrature; Crossover; Anomaly; Sulphides; Lead-Zinc.

\section{Introduction}

The earth's crust is endowed with minerals existing in various forms within it, such as mineral fuels (e.g. coal, petroleum, natural gas, gilsonite, and tar sands), Metallic ores (e.g. iron, manganese, molybdenum, gold, silver, diamond, the platinum group metals, copper, lead, zinc and tin) and Nonmetallic minerals (e.g. phosphate, potash, halite, sand, gravel, limestone and sulfur). 'Mineral Resource' is a concentration or occurrence of material of intrinsic economic interest in or on the earth's crust in such form, quality and quantity that there are reasonable prospects for eventual economic extraction. No matter the shape of the mineral, the most important thing about it is that it could be exploited for the use of man. Technology as it is today could have been unknown without the discovery of minerals and their conversion to meet the need of man (Kudrin, 1989). Minerals constitute the major raw materials upon which technology is founded. All minerals no matter their classifications are found within the earth; to this extent therefore, methods of detecting different kinds of minerals and exploiting them must be developed (Wills, 1985). For any geophysical technique to be useful in mineral exploration, there must be contrasts in the physical properties of the rocks concerned that are related, directly or indirectly, to the presence of economically significant minerals (Milson, 2003).

The very low frequency (VLF) electromagnetic technique has been used here to delineate conductive zones. The technique has been previously used successfully to locate conductive areas (McNeill, 1980) and fracture zones (Olatunji, 1999). The advantages of very low frequency electromagnetic (VLF-EM) method is that, the technique is very rapid, can cover wide area and is cost effective for locating both hidden ores and the structures associated with the mineralization and in use for over 30 years (Fischer et. al., 1983; McNeill \& Labson, 1991 and Bayrak, 2002).

Detailed geophysical and geological prospecting was carried out around Gwani area, Gwaram L.G.A. Jigawa state of Nigeria. The study embarked used the geological exploration techniques to throw light on the mode of occurrence of the suspected mineral in the area. The purpose of this research project is to confirm the occurrence of sulphide mineralization within the study area, using both the geological information and geophysical prospecting techniques. Very low frequency (VLF) electromagnetic method can be used to aid the subsurface mapping of rock type and structure of the area.

\subsection{Location and accessibility of the area}

The area located within sheet 107, (Misau) of the Federal Survey of Nigeria topography series, lies between longitude $10.11363^{\circ} \mathrm{E}$ and $10.13077^{\circ} \mathrm{E}$ and latitude $11.07658^{\circ} \mathrm{N}$ and $11.08307^{\circ} \mathrm{N}$ (Fig. 1). The Gwani town in Gwaram L.G.A. of Jigawa state, Nigeria is accessible by the road from Gwaram through Farin Duste, Fagam and Gwani through Basirka, Sagi (Fig. 2). 


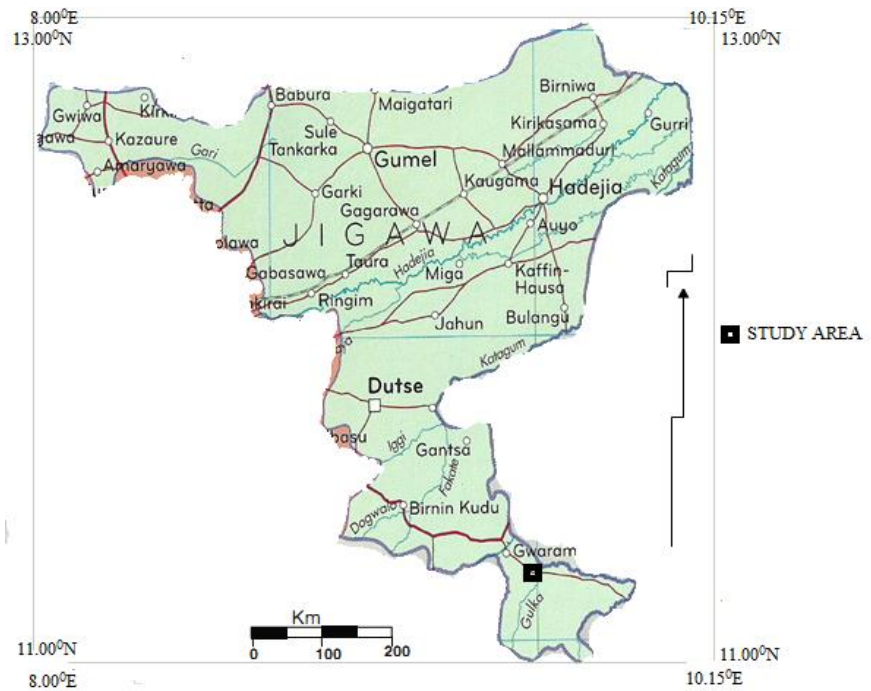

Fig. 1: Location Map of Jigawa State.

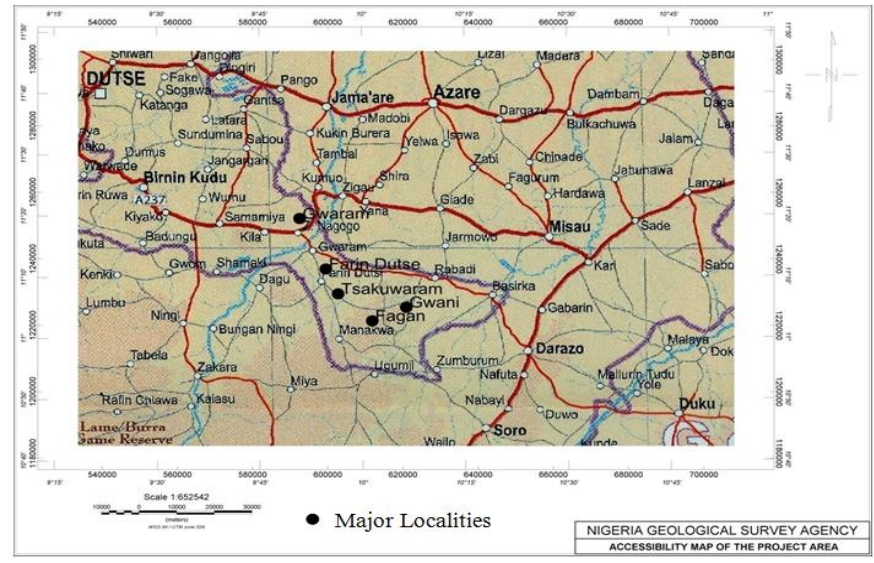

Fig. 2: Accessibility Map of the Project Area.

\section{Regional geology}

The area falls within the Basement Complex of Nigeria (Fig. 3). Falconer et. al. (1911) worked on the geology of northern Nigeria which includes the mapped area, in the course of reconnaissance survey. They recognized the older rocks collectively referred to as Basement complex which composed of migmatites and intruded by granitic rocks called "Older Granites" distinguished from high level intrusive granite of the Jos- Plateau known as the Younger Granite. The area adjacent to the western boundary was described by Wright (1985) and Macleod et. al. (1971) and the rocks identified as migmatite. Eborall (1976) while working on the adjacent area to the north recognized porphyritic biotite hornblende granite, quartz hypersthenes diorite, migmatites and gneisses. She suggested that the complex grades outwards into the less mafic rocks.

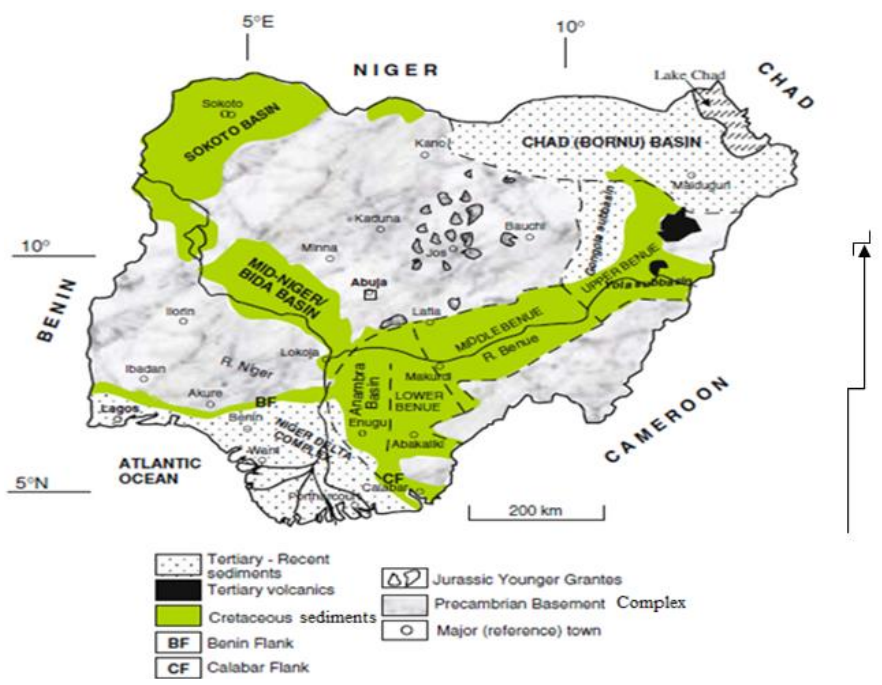

Fig. 3: Geological Sketch Map of Nigeria Showing the Major Geological Components; Basement, Younger Granites, and Sedimentary Basins (Obaje, 2009). 


\section{Geology of the study area}

The Gwani town in Gwaram local government area falls within the basement complex of Nigeria with an altitude of about $600 \mathrm{~m}$ above sea level. "Jan Duste" and "Dalai" outcrop are the two outcrops in the area which belong to older granite suite. The oldest rocks of the igneous series are classed as the coarsely porphyritic biotite granite (Fig. 4) which composed of porphyritic granite and biotite granite.

\subsection{Porphyritic granite}

The porphyritic granites are greenish brown to dark brown colored rocks with a porphyritic texture. The minerals composed of this rock include plagioclase, quartz, K-feldspar, hornblende, Zircon and iron oxide. The phenocryst includes K-feldspar, plagioclase and quartz. They are observed to have perfect crystals with K-feldspar and plagioclase being euhedral while quartz crystals are sub-rounded to rounded. They are all embayed within a quartz-feldspar-matrix with associated hornblende and iron oxide. Zircon occurs as an accessory mineral in the rock. Plagioclase feldspar is zoned and fairly large.

\subsection{Biotite granite}

The biotite granite is coarsely grained, pink in colour and often micrographic. It is composed of anhedral perthite, quartz and biotite. The quartz occurs in clusters separated by intersticial perthite. Biotite shows marginal intergrowth with perthite. Some feldspars and quartz often intergrow forming myremikites. This results from the intergrowing of vernicular quartz and plagioclase which occurs near the rim of the plagioclase crystal. It is a replacement process that causes the formation of the water-like associations of the plagioclases and the quartz (Cox et. al., 1993).

\subsection{Review of geophysical works in the area}

The interpreted Aeromagnetic map of the area (Fig.5) showed a very prominent anomaly trending in N/E-S/W direction. The magnetic survey map (Fig.6) showed that the magnetic anomaly is probably structurally controlled. The two maps show zones of geologic interest. The airborne magnetic map shows at northeastern part that; there is a fault with relative movement and there is magnetic basement trough at the same area.

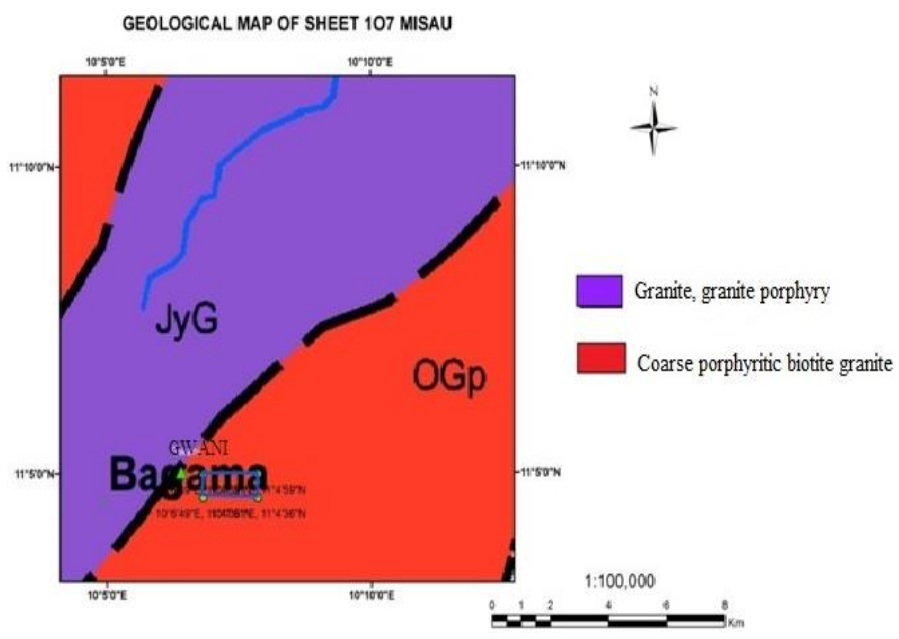

Fig. 4: Geologic Map of the Study Area.

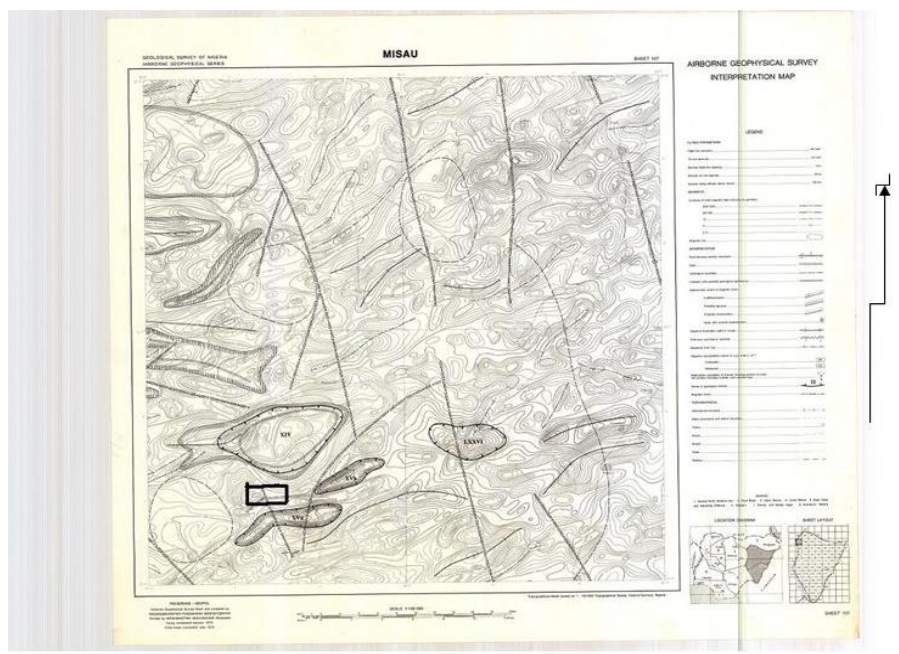

Fig. 5: Interpreted Aeromagnetic Map of Sheet 107, Misau. 


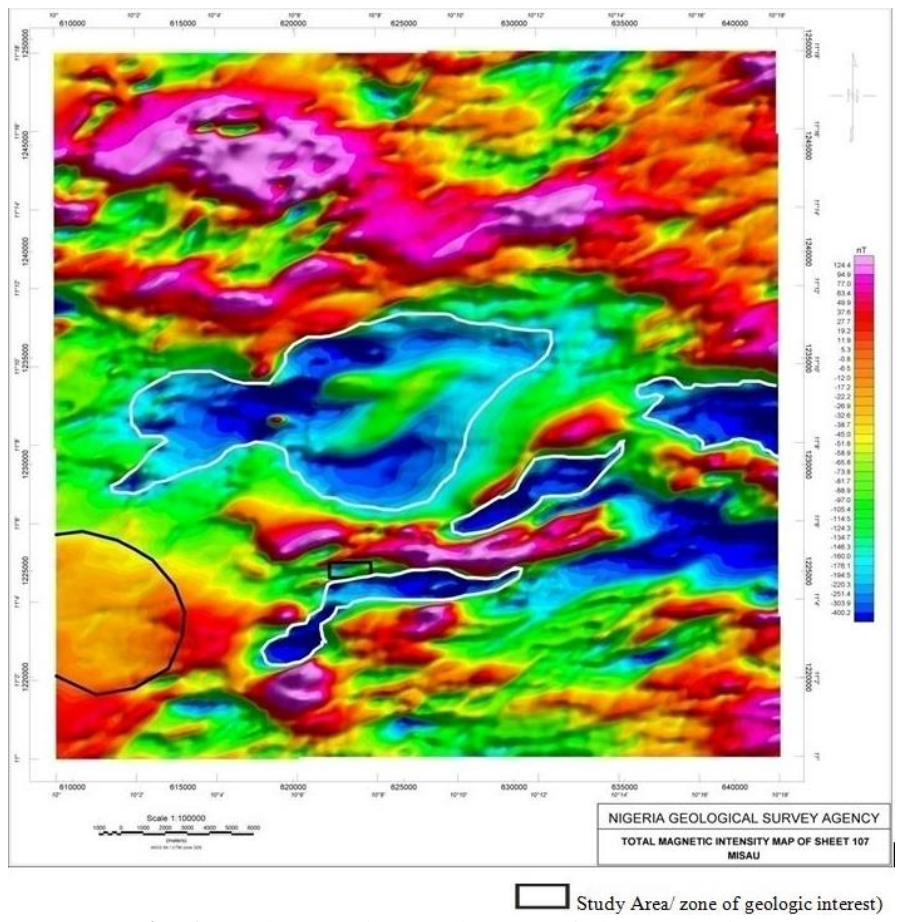

Fig. 6: Total Magnetic Intensity Map of Sheet 107 Misau

\section{Research methodology}

Preliminary work in the survey area took the form of a reconnaissance geological mapping to delineate areas with geological anomalies indicative of possible mineralization (Ariyibi et. al., 2011). This was aimed at studying the geology and selecting geophysical traverses approximately normal to the strike of the geological anomaly. In some cases however, the dense vegetation necessitated the cutting of traverses, although most of the traverses used were along existing roads and footpaths. The field data acquisition involved VLF - EM survey method. Essentially, the VLF - EM measurement was carried out on the chosen traverses located on the delineated area using topographical and interpreted aeromagnetic maps. The potable VLF-EM equipment used for this work was the ENVI VLF (with HWU station) on frequency of $18.3 \mathrm{kHz}$ and it measures both the real and imaginary part of the signal.

\subsection{Data collection}

The survey used VLF-EM waves produced by the transmitter of France having a frequency of $18.3 \mathrm{kHz}$. The survey area was gridded. Data were collected at each grid station (Fig. 12) and the direction of the received primary field is nearly perpendicular to the trending strike of the ore-bearing structural belt.

A total of about 2000 recorded measurement points along 10 profiles were carried out.

Profile Direction= NE-SW direction.

Profile spacing $=50 \mathrm{~m}$.

Profile length $=2000 \mathrm{~m}$.

Stations interval $=10 \mathrm{~m}$.

Total area covered $=9 \times 10^{5} \mathrm{~m}^{2} \equiv 0.9 \mathrm{~km}^{2}$

\subsection{Data reduction}

Data transfer from the VLF equipment to computer was done successfully after the data were acquired. A filtering technique described by Frazer (Frazer 1969) using the equation $f_{2,3}=\left(M_{1}+M_{2}\right)-\left(M_{3}+M_{4}\right)$, where $f_{2,3}$ is the EM data between $M_{1}$ and $M_{2}$ stations and $M_{1}, M_{2}$, $\mathrm{M}_{3}$ and $\mathrm{M}_{4}$ are any four consecutive data points. This was applied to the real component VLF data to transform the data set to the filtered real VLF data (Karous and Hjelt, 1983). The filtered real transform every genuine crossover or inflection points of the real anomaly to positive peaks while reverse cross-over become negative peaks.

Linear graphs were plotted along each profile or survey line; the vertical axis represents the conductivity (inphase) and Quadrature components which are plotted on the same axis and the horizontal axis represents the distance $(\mathrm{m})$ between grid stations along the profiles. The filtering was done using Microsoft excel as well as the graph. Contour map as well as 3D-surface map was produced using Surfer 8 Golden software. 


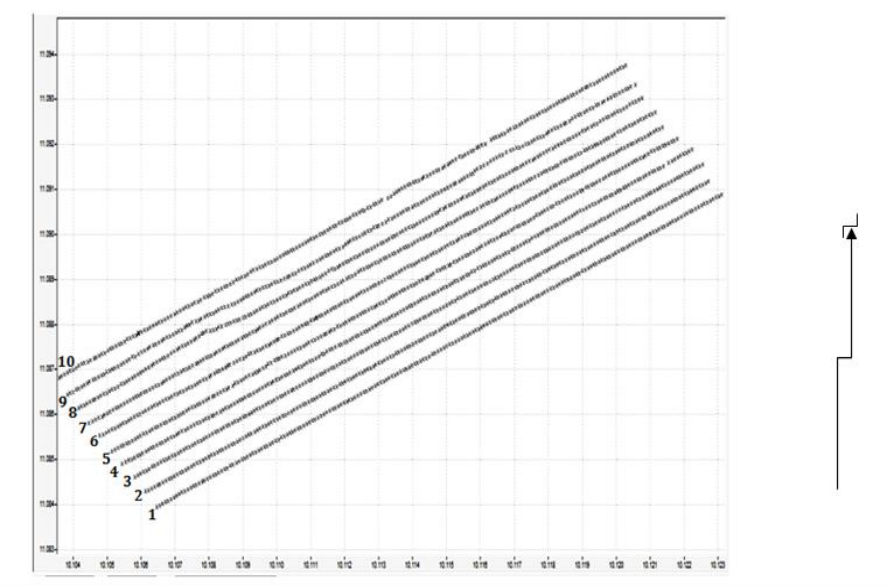

Fig. 12: Acquisition Map of the Survey Area.

\section{Result and deductions from the VLF-EM data}

Plots of inphase and quadrature against distance (stations) of each profile (Fig. 7 and Fig. 8) are present as well as the discussion of the profiles and the depth to the target was estimated by the rule of thumb, the horizontal distance $\left(\mathrm{X}_{\mathrm{D}}\right)$ between the peak positive and peak negative amplitude (Fig. 9) is about twice the depth of burial Z (Olorunfemi, 2010).

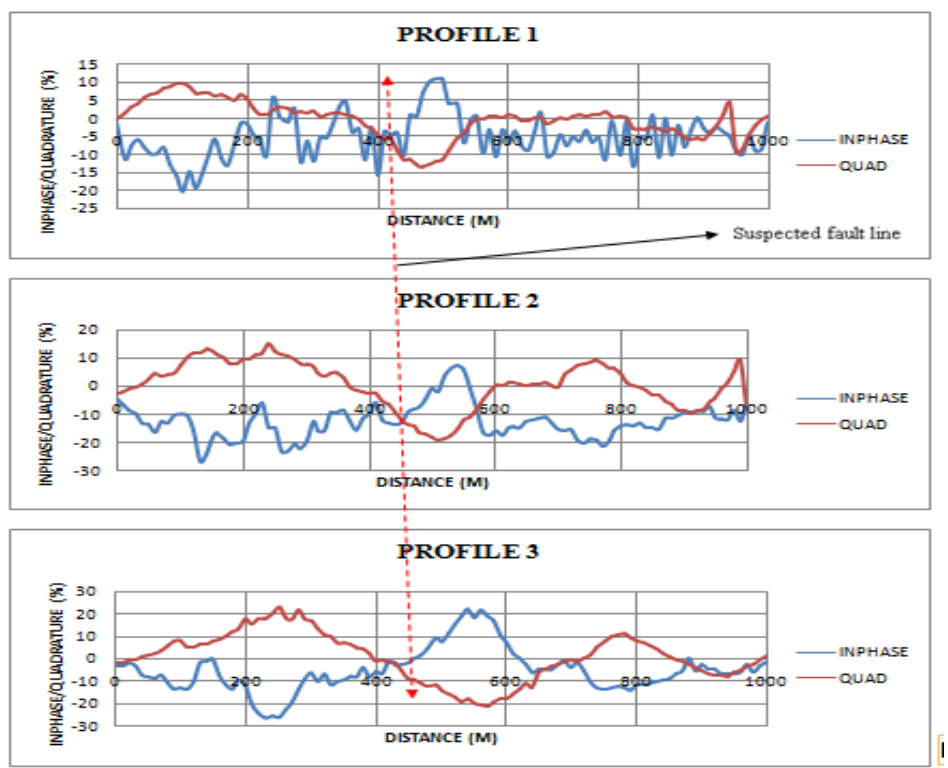

Fig. 7: Graph of Inphase/Quadrature against Distance for Profile 1, 2 and 3. 

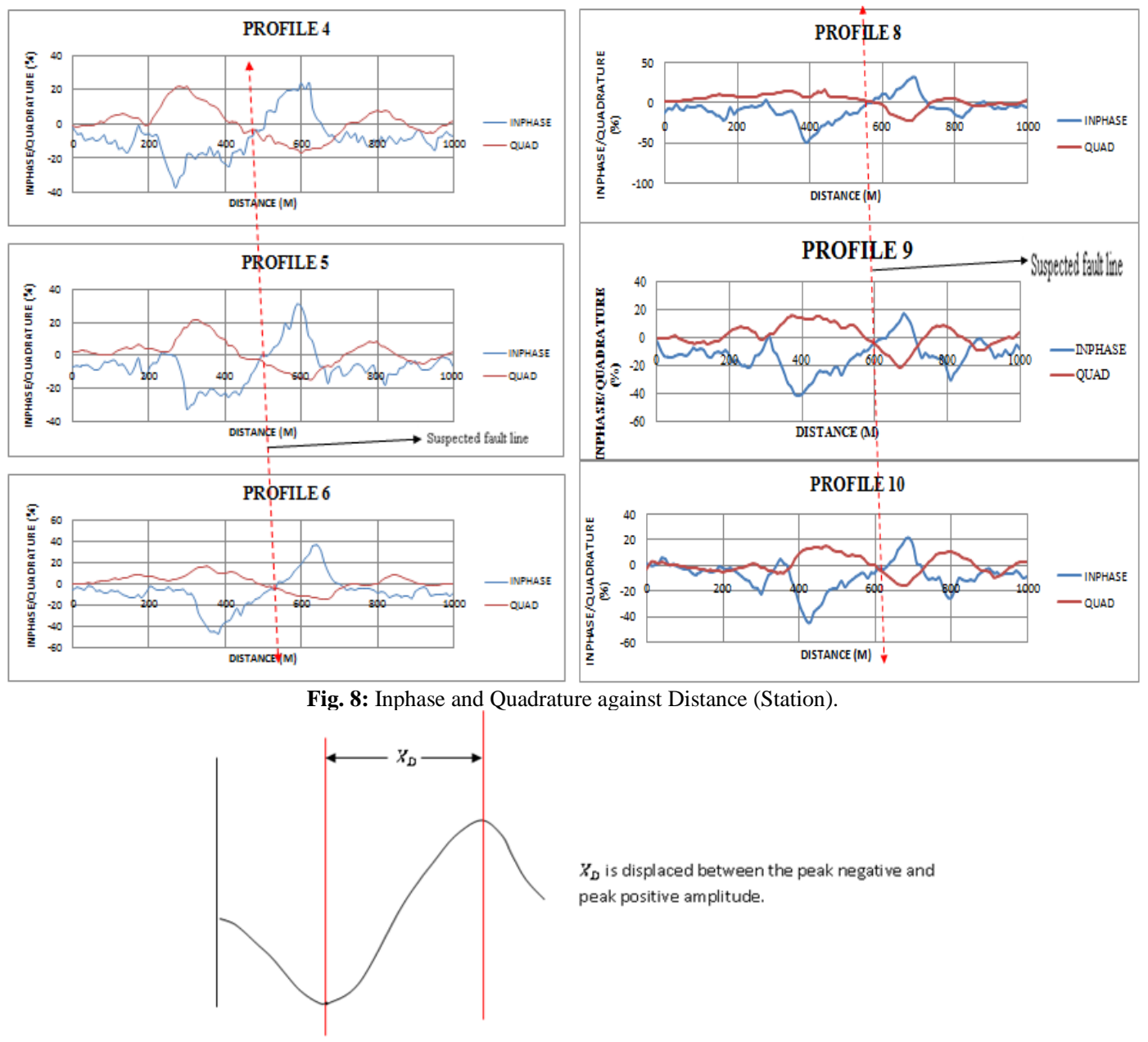

$\mathrm{Z}=0.5 \mathrm{X}_{\mathrm{D}}$

Fig. 9: Schematic of Depth Estimation Graph.

- $\quad$ Survey line/profile 1

Profile one shows the cross-over point (intersection point) at distance $430 \mathrm{~m}$ from the starting point, which indicate the presence of fracture/lineament zone as described by Fraser (1969). It shows that the secondary field (inphase) generated by the subsurface rock around profile one ranges from $-50.4 \%$ to $11.1 \%$. The degree of conductivity of the faulted area is often expressed by the positive inphase responses which exist from $450 \mathrm{~m}$ to about $530 \mathrm{~m}$ at an approximate depth of $45 \mathrm{~m}$.

- $\quad$ Survey line/profile 2

Profile two shows the intersection point at distance $460 \mathrm{~m}$ from the starting point. This cross-over point indicates a fault zone. The inphase responses on the profile vary from $-26.3 \%$ to $+7.3 \%$. The degree of conductivity of this faulted area is expressed by the positive inphaseres ponses; this occurs from $520 \mathrm{~m}$ to $560 \mathrm{~m}$ at an approximate depth of $130 \mathrm{~m}$.

- $\quad$ Survey line/profile 3

Profile three shows the point of intersection at distance $430 \mathrm{~m}$ from starting point which indicates the presence of the suspected fault. In this profile, the inphase responses ranges from $-26.3 \%$ to $+22.1 \%$ while the degree of conductivity of the fractured/faulted zone as indicated by the positive inphase values. This is highest between $460 \mathrm{~m}$ and $620 \mathrm{~m}$ along the profile at an approximate depth of $150 \mathrm{~m}$.

- $\quad$ Survey line/profile 4

Profile four shows the point of intersection at distance $470 \mathrm{~m}$ from the starting point and this indicates the existence of fault zone. The inphase responses vary from $-26.2 \%$ to $+23.7 \%$ respectively. Positive inphase values exist from $510 \mathrm{~m}$ to $650 \mathrm{~m}$ at an approximate depth of $135 \mathrm{~m}$.

- $\quad$ Survey line/profile 5

Profile five shows the intersection point at distance $480 \mathrm{~m}$ from the starting point which indicates the presence of fracture/fault zone. Variation of inphase responses are between $-36.9 \%$ and $+30.8 \%$. Conductivity of the fractured/sheared areas is, shown by a positive inphase values located between $510 \mathrm{~m}$ and $640 \mathrm{~m}$ respectively at an approximate depth of $150 \mathrm{~m}$.

- $\quad$ Survey line/profile 6

Profile six shows the intersection point at distance $500 \mathrm{~m}$ from the starting point which indicates the presence of fault zone. The inphase responses vary from $-32 \%$ to $+36.6 \%$ as shown in the graph. The degree of the conductivity of the fractured area is often expressed by the positive inphase responses which exist from $550 \mathrm{~m}$ to $690 \mathrm{~m}$ at an approximate depth of $135 \mathrm{~m}$.

- $\quad$ Survey line/profile 7

Profile seven shows the suspected fault at distance $550 \mathrm{~m}$ (i.e. intersection point) from the starting point. The positive inphase responses on this profile vary from $-50.4 \%$ to $+36.2 \%$. Positive inphase exists at distance $570 \mathrm{~m}$ to $700 \mathrm{~m}$ along the profile. This probably signifies conductivity of the sheared zones at an approximate depth of $140 \mathrm{~m}$.

- $\quad$ Survey line/profile 8 
Profile eight shows the point of intersection at distance $560 \mathrm{~m}$ from the starting point. This indicates the presence of suspected mineralized fault. The inphase responses are ranges from $-50.4 \%$ to $+29.5 \%$ along this profile. The positive inphase responses are located between $570 \mathrm{~m}$ and $720 \mathrm{~m}$ at an approximate depth of $145 \mathrm{~m}$.

- $\quad$ Survey line/profile 9

Profile nine shows the intersection point at distance $610 \mathrm{~m}$ from the starting point; this cross-over point indicates a fault zone. The inphase responses on the profile vary from $-41.4 \%$ to $+17.6 \%$. The degree of conductivity of this faulted area is expressed by the positive inphase responses; this occurs from $630 \mathrm{~m}$ to $710 \mathrm{~m}$ at an approximate of $145 \mathrm{~m}$.

- $\quad$ Survey line/profile 10

Profile ten shows the intersection point at distance $620 \mathrm{~m}$ from the starting point which indicates the presence of fracture/fault zone. Variation of inphase responses are between $-44.4 \%$ and $+20.8 \%$. Conductivity of the fractured/sheared areas is, shown by a positive inphase values located between $630 \mathrm{~m}$ and $720 \mathrm{~m}$ respectively at an approximate depth of $125 \mathrm{~m}$.

\section{Interpretation}

The main aim of using the VLF method here is to identify mineralized fracture or lineament zones. The graphs of inphase and quadrature components were plotted against distances along each survey line (Fig. 7 and Fig. 8). The cross-over points (i.e. point of intersection of inphase and quadrature plots) sometimes indicate fracture/lineament zones (Fraser, 1969). It is sometimes associated with vertical contact between intrusive materials and the country rocks (Telford et al, 1990). The positive quadrature values indicate possible fault zones (Aneke, 1988). The negative ones are likely, due to near surface targets/conductors and hence can confuse the interpretation (Fraser, 1969). These surface conductors are separated from the subsurface ones by separating the negative quadrature signals from the positive ones.

In an effort to reduce erroneous interpretation of VLF data caused by geological noise component generated from the transmitted frequency, Fraser filtering technique was applied on the entire inphase data for numerical filtering purposes as suggested by Fraser (1969). The new sets of data obtained were then contoured. This method transforms the zero crossing in the plots (Fig. 7 and Fig. 8 ) into peaks. This filtering reveals clearly area of high and low conductivities by improving the resolution of anomalies to ease their recognition. A positive peak indicates a conductive area (Fraser, 1969). All negative values in the filtered data were ignored as advised by Fraser (1969), as they will only confuse the expected picture. The plots show one identical anomaly which is suspected to be hydrothermal zone or mineralized fault.

The filtered VLF contour (Fig. 10) indicate the area of high conductivity at Southwest of the map, which is possibly the fractured/faulted zone associated with the mineralization. Also, the 3D-surface map (Fig. 11) confirmed the presence of conductive body at that same location. Finally, since the conductivity within this area is high, it can be inferred that the deposit is expected to be economically viable and the mineralization trends northwest ward which is probabbly the subsurface strike.

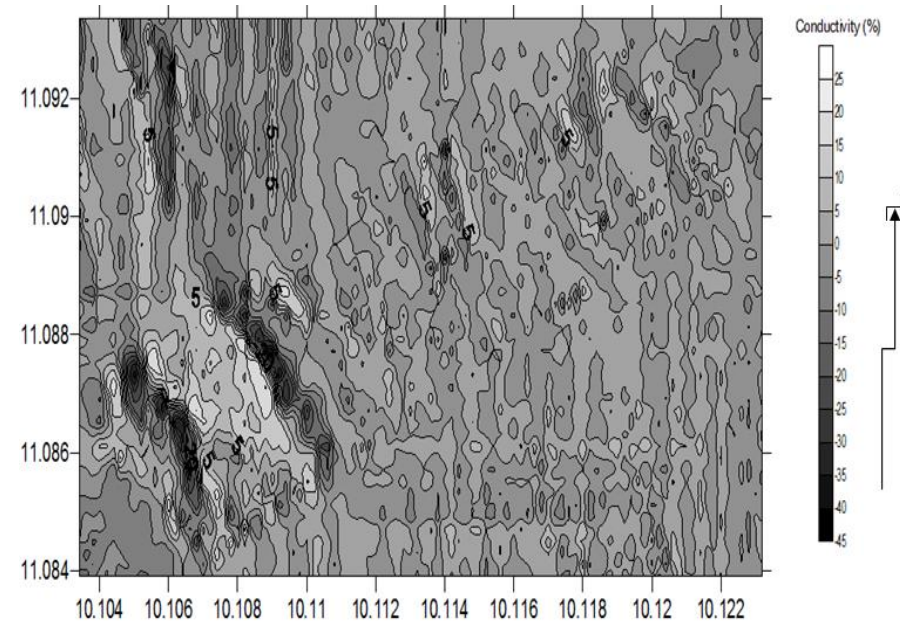

Fig. 10: Conductivity Contour Map of the Survey/Project Area Produced Using Surfer 8 Golden Software.

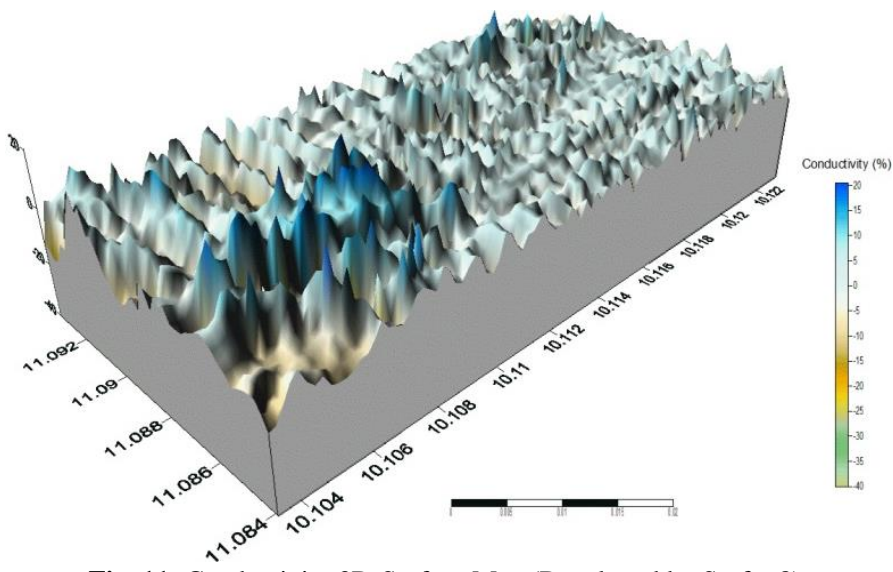

Fig. 11: Conductivity 3D-Surface Map (Developed by Surfer 8). 


\section{Conclusion}

The VLF tecnique is one of the most common methods of reconnaisance in electromagnetic surveys and amounts of data are being collected world wide.To allow and facilitate a qualitative interpretation of VLF data, a very fast iterative method has been developed to transform zero-crossings in to positive peaks (Fraser, 1969). It is however significant to note that the VLF-EM method does enhance chances for inferrring the presence of fracture/linearment as well as mineralized zone. The VLF map as produced after Fraser reduction, revealed the areas of high and low conductivity within the subsurface materials. The map show non-uniformity in the conductivity of the subsurface materials within the study area. The conductivity is very at the southwest of the VLF contour map.

Therefore, for reconnaisance purposes, the VLF method of geophysical prospecting employed in this work is quite adequate for fractures/fault delineation and finally, since the conductivity within this area is high, it can be inferred that the deposit is expected to be economically viable and the mineralization trends northwest ward which is probabbly the subsurface strike.

\section{Acknowledgments}

My appreciation goes to Professor O. K. Likkason of Physics Department, Abubakar Tafawa Balewa University Bauchi. Also, prefound gratitude goes to Mr. Arobasalu O .T. (former head of Geophysics Department, NGRL Kaduna) and the entire staff of Nigerian Geological Survey Agency(NGSA) for given me the oppurtunity to excell. Finally, a big thanks goes to the authors whom their works were cited in this research.

\section{References}

[1] Aneke SC (1988): A composite Geophysical Investigation of Burum Dolomitic Marble, FCT

[2] Abuja, Unpublished M.Sc. Thesis ABU Zaria.

[3] Ariyibi EA, Folami SL, Ako BD, Ajayi TR and Adelusi AO. (2011). Application of the principal component analysis on geochemical data: a case study in the basement complex of Southern Ilesa area, Nigeria. Arabian Journal of Geosciences, 4(1-2), 239-247. https://doi.org/10.1007/s12517010-0175-5.

[4] Bayrak M. (2002) Exploration of Chrome Ore in Southwestern Turkey by VLFEM. Jour of the Balkan Geophy Society 5: 35-46.

[5] Cox KG, Bell JD and Pankhurst RJ (1993): Interpretation of Igneous Rocks. Chapman and Hah; London pp. 176-187.

[6] Eborall MI (1976) Intermediate rocks from older granite complexes of the Bauchi area, northern Nigeria. Geology of Nigeria, 65-74.

[7] Falconer JD, Longbottom A, and Woods H (1911) the Geology and Geography of Northern Nigeria. Macmillan and Company LTD, London. 295

[8] Fischer G Le Quang BV, Muller I (1983) VLF Ground Surveys, a Powerful Tool for the Study of Shallow 2-D Structures. Geophys Prosp 31: 977991. https://doi.org/10.1111/j.1365-2478.1983.tb01100.x.

[9] Fraser DC (1969). Contouring of VLF-EM data. Geophysics, 34(6), 958-967. https://doi.org/10.1190/1.1440065.

[10] Karous M, and Hjelt SE (1983). Linear filtering of VLF dip-angle measurements. Geophysical prospecting, 31(5), 782-794. https://doi.org/10.1111/j.1365-2478.1983.tb01085.x.

[11] Kudrin V (1989): Steel making (2nd Ed) MIR Publisher, Moscow.Lagos, pp 347-358

[12] Macleod WN, Turner DC, \& Wright EP (1971). The geology of the Jos Plateau, Vol. 1: General Geology. Geol. Surv. Nigeria Bull, 32. 1-119.

[13] McNeill JD, and Labson VF (1991). Geological mapping using VLF radio fields. In Electromagnetic Methods in Applied Geophysics: Volume 2, Application, Parts A and B (pp. 521-640). Society of Exploration Geophysicists. https://doi.org/10.1190/1.9781560802686.ch7.

[14] McNeill JD (1980). Electromagnetic Terrain conductivity measurement at low induction numbers (Tech. Note) TN-6, Geonics Ltd., Mississauga, Canada, $15 \mathrm{pP}$.

[15] Milson J (2003). Field Geophysics: the Geological Guide Series. John Wiley \& Sons Ltd, England (3 ${ }^{\text {rd }}$ ED). 1-25pp. ISBN 0-470-84347-0.

[16] Obaje NG (2009). Geology and mineral resources of Nigeria (Vol. 120). Springer. https://doi.org/10.1007/978-3-540-92685-6.

[17] Olatunji S (1999). Geophysical Site Investigation of the Federal College of Education (F.C.E), Zaria, Nigeria Unpublished MSc. Thesis, A.B.U., Zaria.

[18] Olorunfemi MO (2010): electromagnetic (EM) methods of geophysical prospecting (unpublish). Pp40, 45.

[19] Telford WM, Telford WM, Geldart LP, Sheriff RE, and Sheriff RE, (1990). Applied geophysics (Vol. 1). Cambridge university press. https://doi.org/10.1017/CBO9781139167932.

[20] Wills BA (1985): Mineral processing technology ( $3^{\text {rd }}$ edition), Oxford.

[21] Wright JB, Hastings DA, Jones WB, and Williams HR (1985). Geology and mineral resources of West Africa (Vol. 187). London: Allen \& Unwin. 